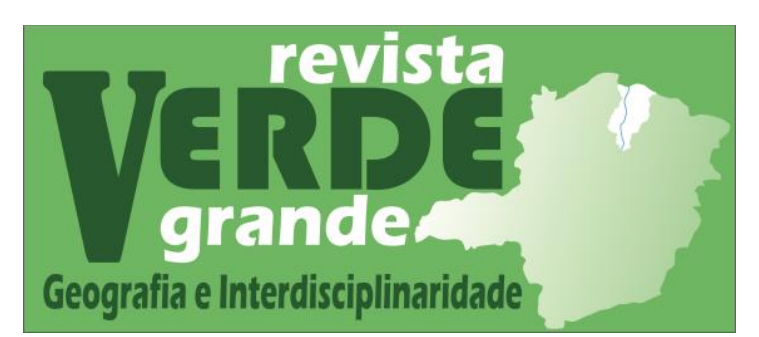

Volume 01, n‥ 01, 2019

https://www.periodicos.unimontes.br/index.php/verdegrande

\title{
CARTA DAS ÁGUAS
}

Paulo de F. Ribeiro ${ }^{1}$ https://orcid.org/0000-0002-3282-7702

\footnotetext{
${ }^{1}$ Sociólogo. Secretário Municipal de Meio Ambiente e Desenvolvimento Sustentável de Montes Claros-MG. E-mail: opinimov@gmail.com
}

Entre os dias 07 a 10 de setembro de 2017 expedicionários cruzaram o sertão mineiro, em três roteiros contemplados na V Edição da Expedição Caminho dos Geraes: Roteiro Serra do Cabral, Roteiro Botumirim/Espinhaço e o Roteiro Peruaçu. O projeto socioambiental idealizado pela Secretaria Municipal de Meio Ambiente e Desenvolvimento Sustentável em parceria com a Fundação Cultural Genival Tourinho, o Instituto Estadual de Florestas - IEF, as Universidades Federal de Minas Gerais - UFMG e Estadual de Montes Caros - Unimontes, ONG's, sociedade civil organizada e apoiado pela iniciativa privada, com o objetivo de avaliar a situação do patrimônio natural da região, catalogando espécies e avaliando possíveis danos ambientais, além de mapear os atrativos turísticos da região. A Carta das Águas consolida informações, impressões e, sobretudo, o clamor do povo gerazeiro para a salvação de suas nascentes e de todo o patrimônio natural em risco eminente de desaparecimento para o usufruto das gerações futuras.

Imortalizado pela obra do escritor Euclides da Cunha, Os Sertões, mantemos firme o sentimento de que o sertanejo é antes de tudo um forte e buscamos forças não apenas para resistirmos, mas, nesses novos tempos termos a capacidade de resiliência que a convivência com a seca nos impõe.

A origem da palavra "sertão" é controversa. Alguns linguistas afirmam ser derivada de um vocábulo de origem angolana: "muceltão", que remete a "lugar interior", "terra entre terras", "local distante do mar". O vocábulo angolano teria sido alterado para "celtão" e depois "certão" até adquirir a forma atual "sertão".

Outra versão, mais aceita, atribui a palavra "sertão" ao étimo latino "desertanu", utilizado para designar regiões interioranas, longe do litoral, porém, não necessariamente de clima árido e que teria sido modificado para "desertão" e depois, apenas "sertão". 


\section{Carta das Águas}

Paulo de F. Ribeiro

Seja qual for sua origem, a verdade é que a palavra "sertão" pode adquirir significados bastante distintos, porém é sempre empregada para designar locais pouco habitados ou onde predominam costumes antigos em contraposição às regiões desenvolvidas.

No período colonial brasileiro, "sertão" era frequentemente empregado para designar as terras ainda não exploradas do interior do país, pouco habitadas, de difícil acesso e, por isso, pouco desenvolvidas. Com o tempo, e a colonização de grande parte dos "sertões", a definição mais comum ficou atrelada às regiões que compõem o semiárido brasileiro, mas também são chamados de "sertão" os interiores de Mato Grosso, Goiás, e até mesmo do Amazonas no sentido de regiões pouco povoadas.

De qualquer forma, a palavra "sertão" está intimamente relacionada com a história e a identidade sociocultural, principalmente das regiões nordeste do Brasil e Norte de Minas Gerais, especialmente aquelas retratadas pela obra Grande Sertão Veredas do escritor mineiro Guimarães Rosa.

Euclides da Cunha, Guimarães Rosa, Graciliano Ramos cada um a seu modo, retrataram os sertões e os sertanejos pontuando sempre a peleja da vida na travessia arriscada e teimosa, ainda que bela, de lidar com a escassez de água e tantos outros recursos.

Essa, portanto, foi a tônica da $\mathrm{V}$ Expedição Caminhos dos Geraes, que buscou percorrer três distintos roteiros que têm em comum a convivência com a escassez de água e o abandono de políticas públicas em benefício às populações tradicionais.

O Norte de Minas Gerais tem sido um espaço de exploração predatória dos recursos naturais, desde a chegada dos portugueses, tanto os que vieram pelo norte via rio São Francisco, quanto os que vieram pelo sul, com as bandeiras. Nas primeiras incursões no século XVI o objetivo era o saque de ouro e pedras preciosas, assim como a captura de índios e negros para o trabalho escravo.

São praticamente cinco séculos de maus tratos com a natureza. Foi forjada aqui, de forma lenta, mas profunda, uma cultura de descaso para com a natureza. A região foi um espaço de violência para com os índios, a riqueza mineral, vegetal e a fauna. O garimpo, a extração de madeira, a criação de gado, a produção de carvão, o eucalipto, a irrigação, a pesca predatória e a mineração compõem uma interminável lista de ações contributivas para a calamidade ambiental que estamos vivendo. Praticamente todo o Norte de Minas está, desde a década passada, na lista mundial de regiões suscetíveis à desertificação.

Um estudo encomendado pelo Ministério do Meio Ambiente, há cinco anos, apontou uma tendência de desertificação. Diante de dados ambientais atuais, é possível avaliar que apesar do Norte de Minas ser a região mais preservada do estado, com mais de $50 \%$ da 


\section{Carta das Águas}

Paulo de F. Ribeiro

vegetação original intacta, ainda assim, essa premissa não impede a confirmação dos dados catastróficos do referido estudo. É preciso considerar que a porção Norte do estado passa por estiagens extremas, influência da maior atividade solar e das correntes quentes provenientes do Atlântico. A seca dos últimos cinco anos é o ápice de um ciclo climático, com períodos que variam entre 80 e 100 anos.

O modelo de desenvolvimento regional concentrador de riquezas por um lado, e, por outro expropriador do trabalho dos mais pobres e da natureza foi denunciado, com base em muitas pesquisas, por Celso Furtado na década de 1950. Desde então, a situação no Norte de Minas se agravou. Ficou para o Norte de Minas a parte mais perversa e depredadora da produção capitalista, ou seja, a superexploração do trabalho e a exploração dos recursos naturais.

A subordinação da economia regional aos interesses da monocultura de eucalipto, dentre outros, levaram à região ao impasse atual. A água de superfície foi reduzida drasticamente a ponto de não ser suficiente nem mesmo para o consumo humano. A abertura de poços tubulares, cada dia mais profundos, está comprometendo irremediavelmente a reserva de água em toda a região. As outorgas de água do subsolo para os grandes empreendimentos pecuários, de monoculturas de eucalipto e irrigação, de forma geral, estão acelerando o processo de desertificação do Norte de Minas.

Pesquisadores dos recursos hídricos afirmam que a monocultura do eucalipto é a principal consumidora da água existente. A cada mil milímetros de água que cai na nossa região, o eucalipto consome oitocentos. O cerrado, bioma predominante na região, com uma variedade riquíssima de árvores precisa, para sua sobrevivência, DE quinhentos milímetros de água para a sua sobrevivência. Como na região a média histórica das chuvas é de mil e cem milímetros, há um déficit de duzentos milímetros. Além disso, há o consumo humano, a dessedentação animal e o plantio de lavouras que necessitam de água.

Chegamos à conclusão óbvia: a conta não fecha. Ou seja, em regiões onde chove menos de mil e quinhentos milímetros a cultura do eucalipto é inviável e, portanto, deve ser proibida ou intensificadamente monitorada. Não se pode permitir que florestas de eucalipto se mantenham de pé em detrimento aos ecossistemas locais e à vida das pessoas. O que nos permite apontar que é chegado o fim da linha, brecamos agora ou as futuras gerações não mais conhecerão nossas veredas, o pantanal mineiro e tantas outras belezas e preciosidades a não ser pela descrição primorosa dos autores que vislumbravam no sertão e, no sertanejo, um universo diverso e profundo, só passível de ser entendido quando vivenciado. 


\section{Carta das Águas}

Paulo de F. Ribeiro

Para auxiliar no processo de entendimento dos processos socioambientais vividos, a $\mathrm{V}$ Expedição Caminhos dos Geraes, pretendia mostrar tanto as belezas naturais quanto os impactos ambientais vividos na região. Diversos e complexos, os processos socioambientais vividos retratam uma realidade assustadora para a sociedade norte mineira que cada vez mais se vê próxima de uma catástrofe ambiental.

Foram realizados os roteiros da Serra do Cabral, roteiro Botumirim / Espinhaço e o roteiro do Peruaçu. Esses três roteiros, apesar da distância geográfica que os separam, apresentam problemáticas socioambientais semelhantes e necessitam de intervenções urgentes para que se possam amenizar os impactos ambientais vividos.

Ressaltamos que a situação vivida é de iminente desastre ambiental com aceleração do processo de desertificação que, a cada dia, agrava-se em decorrência de incêndios, pela escassez de chuvas e pela redução do êxodo rural, que nas décadas de 50, 60 e 70 se intensificava em virtude das longas estiagens. E, na tentativa de viabilizar esforços coletivos e institucionais que propiciem a solução desses problemas, os participantes da V Expedição Caminhos dos Geraes, representando a sociedade norte mineira, apresentam ao Excelentíssimo Governador de Minas Gerais as seguintes demandas:

1 - Proibição de novas áreas para plantios de eucalipto;

2 - Monitoramento dos níveis freáticos para que haja novos parâmetros para emissão de outorga no Norte de Minas;

3 - Ampliação do Parque Estadual Veredas do Peruaçu a partir da aquisição de terras de proprietários que possuem dívidas com o estado e estão dispostos a negociar; 4 - Criação do Parque Estadual de Botumirim, importante reserva para a manutenção da biodiversidade e dos mananciais hídricos;

\section{5 - Cercamento da área pantanosa de Pandeiros.}

Certos da sensibilidade do Excelentíssimo Senhor Governador, que tem amparado o Norte de Minas Gerais, os Vales do Mucuri e Jequitinhonha com Programas Especiais para a convivência com a seca, vimos, respeitosamente solicitar o seu imediato e intenso esforço no sentido de dar as providências necessárias para que coloquemos fim ao intenso processo de desertificação pelo qual está passando a região norte mineira. Salvemos o sertão e os sertanejos! 